\section{CLINICAL REMARKS}

on

\section{REPEATED HEMOPTYSES IN NON-TUBERCULOUS SUBJECTS, WITH ILLUSTRATIVE CASES.}

By DAVID NEWMAN, M.D., F.F.P.S.GLASG., Surgeon to the Glasgow Royal Infirmary; late Surgeon in Charge of the Department for Diseases of the Throat and Nose.

Six years ago I brought under the notice of the members of the Pathological and Clinical Scciety of Glasgow a subject which at that time was of considerable interest to me, namely, frequently repeated hæmoptyses in persons who were not suffering from phthisis pulmonalis; and since then so many cases of hæmoptysis of this kind have come under my observation that the subject appears to me to be worthy of further attention.

Although the precise cause of the hæmoptysis varies considerably in the different cases, both in those previously reported and in the cases now brought forward, still they all have one important practical fact in common, namely, the hæmoptyses were believed at one time to be due to tuberculous disease of the lung, while ultimately they proved to be the result of a lesion in the upper air channels.

The tissues in these passages having a very free vascular supply, and being exposed to injury, blood vessels already weat-oned by disease are liable to rupture, and so give rise to small hæmoptyses, and, after these bleedings have ceased, in some instances almost no trace of the hæmorrhages can be discovered unless by very careful and frequently-repeated examinations. No one will argue that hæmorrhage is likely to proceed from a previously healthy mucous surface; but it is undoubted that hæmorrhages do occur from comparatively trivial lesion of the larynx and pharynx, and are attributed not to their proper source but to pulmonary tuberculosis, even in the absence of physical signs of that condition.

Hæmoptysis is looked upon by the public and by most general practitioners as of great significance, being regarded as a danger signal for phthisis pulmonalis, and a condition not to be lightly considered or carelessly treated, even although unaccompanied by any symptoms or physical signs of pulmonary disease. But while in not a few cases minute hæmorrhages are the first indication of tuberculous disease of the lung, every physician must have met with cases of hæmoptysis where no serious results have followed. Hæmoptysis, or blood spitting, having its source in pulmonary or bronchial hæmorrhage, is usually easy of diagnosis; but, as I shall point out presently, it is not always so. A hæmorrhage which appears to be derived from the parenchyma of the lung or from the bronchioles may originate in other parts, and find its way into the trachea.

A patient may have a hæmoptysis and at the same time may be suffering from more or less acute laryngitis, and blood may actually be seen in the larynx, but because of this we have no right to assume that the hæmorrhage is not from the lungs. Because no abnormal physical signs can be detected in the chest at the time is no reason why we should exclude the possibility of the hæmorrhage being pulmonary. It is indeed held by those who have had a large experience of pulmonary disease that in many cases there is a complete absence of the symptoms and physical signs of phthisis in the stage of early hæmoptysis. And I have shown elsewhere ${ }^{1}$ that phthisis ab hamoptöe may originate from blood. derived from the upper air passages, and inspired into the minute ramifications of the lung, instead of, as is commonly the case, from the blood vessels within the substance of the organ.

Undoubtedly in most cases hæmoptysis is indicative of pulmonary disease, or is at least suggestive of a grave lesion, either in the lungs or in the upper air passages. In some cases, however, as will be shown presently, the laryngoscope gives us the means of discovering purely local causes of hæmorrhage.

A hæmoptysis is often the first symptom which induces the patient to seek medical advice, and not infrequently the patient has an explanation of his own to offer as a reason for the bleeding. The causes of hæmoptysis are often lost sight of both by the laity and by medical practitioners, and they speak of "blood spitting" and "bleeding from the lungs" as being synonyrous. If it is clear that the blood is not coming from the gums or the mucons membrane of the mouth and tl ere is no general constitulional malady, such : s hæmophilia, purpura, scurvy, or any of the forms of anærr ia, the conclusion is at once come to th: $t$ the patient is thr atened with phthisis. The mental effect which " a bleeding" produces on the individual affected by it is often very marked, and even when he is assured as to the innocent nature of the lesion causing the loss of blood, he may take a long time to recover from its depressing mental effect. And doubtless also the history of a hæmoptysis greatly influences the prognosis of the medical attendant.

I have seen a considerable number of cases where patients have been told that they are suffering from phthisis, and some of them have been recommended to go abroad, where a laryngoscopic examination has revealed the true source of the blood and relieved the patient from the fear of grave consequences.

Excluding diseases characterised by changes in the blood or blood vessels which permit the escape of blood on the mucous surfaces, and without attempting to give anything like a complete list of the lesions, which may cause an extravasation of blood into the larynx or pharynx, the causes of hæmorrhage from these parts may be classified as follows: Acute inflammation, and the various forms of ulceration of the mucous membrane (these are causes too obvious to require illustration or remark). The less evident lesions are more likely to be overlooked, such as varicose veins, or small varicose aneurysms in the mucous membrane; very vascular tumours in the larynx, at the base of the tongue, or in the naso-pharynx.

In describing the cases I shall only refer to points in their history bearing upon the hæmoptysis, and for illustration I shall select cases which have been under observation for three years or more, and so obviate, as far as may be possible, errors in diagnosis. Before describing these I may refer in a word or two to the cases previously published, ${ }^{2}$ and their subsequent history as far as is known.

\section{Epitome of Old Cases.}

1883. CASE I.-Aged 49, frequent hæmoptysis for sixteen months, vary ing from a few drops to one ounce and a-half, attributed by physicians to phthisis; without physical signs in chest, but expectoration tinged with blood for some time after the hæmoptysis. Patient anæmic and emaciated from anxiety and loss of appetite. At fourth examination, with laryngoscope, source of hæmoptysis with difficulty discovered to be from bleeding points below anterior commissure. When treated patient enjoyed perfect health ; no recurrence of hæmoptysis.

pred hemoptysis for nine months, 1883. CASE II.-Aged 56, small repeated ha after a hæmorrhage trache feurr deeply injected, and erosion of mucous membrane below cricoid hypd heræmia disappearer treatment for six months, cure, no recurrence twenty-six days. Under treatment pulmonary disease.

189. Generai health poor, but no pula homoptysis in 1879 , one pint of blood 186. CASE IIr.-Aged 35, profuse hrom six to freely mixed with air ; frequent hæu no pain or physical signs in chest. elghteen months till 1886; cough, but no pain or phy of phthisis. After Pale and anæmic, much mental deeply bloodstained, and streaks of blood hos parior pharyngeal wall. Larynx and trachea healthy, but varicose veins on pharyngeal arch. Veins closed by electrolysis. No recurrence reported well 1890 .

In these cases the patients complained of "blood spitting" only, but undoubtedly also suffered in health from the alarm produced by the fear of phthisis, as in each individual case competent physicians had expressed the opinion that the hæmoptysis was from the lungs.

Of all the local causes of hæmorrhage from the upper air passages dilated veins in the pharynx or the larynx is the part here. From this source the bleeding is generally small, and seldom does more than tinge the mucus or saliva, but even although not large in amount the bleeding may be persistent. The following case may be taken as an illustration:

CASE IV. Repeated Hamoptysis during Seventeen Months, said to be due to Phthisis; Voice Hoarse, from Hypertrophic Laryngitis ; Hemorrhage due to an Erosion of the Mucous Membrane and Passive Hyperemia.-J. C., aged 27, consulted me at the Royal Infirmary in November, r889. The patient complained of weakness, and said that during the previous seventeen months he had suffered from a cough, which troubled him most when at his work, and that at least on six occasions he had noticed the expectoration mixed with blood, but the quantity so coughed up was never great. The blood always came up easily, sometimes fluid, at other times in the form of small clots. The bleeding seldom lasted more than a few days,

[1900] 
mixed with the blood. The cough was not accompanied by pain in the chest, but was so persistent that he consulted several doctors, who told him when he mentioned the "blood-spitting" that he was very probably suffering from phthisis. Under ordinary circumstances the expectoration was mucous, but for some time after the hæmoptysis the sputa were tinged with blood. The blood was usually noticed in the sputa after some considerable exertion, but on one occasion the hæmorrhage occurred in the morning. The voice had been hoarse for three or four months, but this came on so gradually that the patient had difficulty in fixing the date of its onset. He was poorly nourished, and his occupation, that of a steel worker, exposed him to rapid and considerable variations in temperature. He had a feeble circulation, and suffered from varicose veins in both legs, from a left varicocele; the veins of the face and neck were very distinctly marked, and the thyroid gland was enlarged in both lobes. The cardiac sounds were feeble, but free from murmur or accentuation, and there was no evidence of enlargement or dilatation of the heart. The liver dulness was not increased, and there was no albuminuria, nor were tube casts discovered. The lungs were carefully examined on several occasions, and, beyond a possible want of due resonance at both bases behind, nothing abnormal could be made out. Inspection of the air passages after a bleeding showed the larynx and trachea to be tinged with blood. and also a few streaks were seen on the posterior wall of the pharynx. Two days after, on examining the throat, the patient was observed to be suffering from chronic hypertrophic laryngitis; on the mucous membrane of the false cords there were several distended veins and some submucous hæmorrhages, and in the anterior aspect of the left arytenoid cartilage there was a distinct erosion, which disappeared within ten days. But the same appearances were noticed af cer a subsequent hæmoptysis. The chest was carefully examined on many occasions between November, 1889, and July, r892, by Dr. McKellar Dewar and myself, and no physical sign of disease could be made out. Under local and the patient reported himself well at the beginning of 1894 , when he was last seen and examined.

CASE v.-History of repeated Small but Prolonged Hamoptyses, and Pleurisy of Old Standing, pronounced due to Phthisis in 1879 . Blood from Spot in Jung8.-A. B.. aged 47, came under my observation in November, 1885 , when I was asked by the late Dr. Robert Smart to see the patient in consultation with him. From the history, it appeared that the patient had small hæmoptyses for seven years, varying in amount, and coming on at intervals of from one to three months; he also had an attack of pleurisy
involving the base of the left lung, which confined him to bed for three involving the base of the left lung, which confined him to bed for three
weeks in the autumn of 1873 , but from it he made a good recovery. He, weeks in the autumn of 1873 , but from it he made a good recovery. He, however, complained of a chronic cough with considerable mucous expectoration. Under ordinary circumstances the expectoration was was sometimes tinged with blood for some hours. When the hæmoptysis occurred during the day, the blood expectorated was almost pure and sometimes clotted, but when the bleeding came on in the morning the mucus was mixed with it. He had no pain in the chest, and the temperature was normal. The patient was pale and thin, but had not emaciated during the last seven years. In 1879 he consulted two physicians in London, along with Dr. Smart, and they both attributed the hæmoptysis to phthisis pulmonalis, but the grounds upon which the diagnosis was made are not known to me. The patient was able to follow his occupation, but was much depressed by the repeated expectoration of blood, and his appetite was poor. Careful physical examination of the chest failed to Immediately after a hæmoptysis had passed, I examined the air passages, and found a small, highly-vascular area about $\frac{1}{4}$ inch square, on the posterior wall of the naso-pharynx. There was no blood issuing from it, but on touching it with a probe an attack of coughing was at once brought on, and the patient complained of great irritation and pain in the spot, tion the same condition was found, and by applying the probe again similar effects followed. There was some granular pharyngitis, and the vocal cords were slightly congested, but otherwise the air passages were
normal. After a third examination fused chromic acid was applied to normal. After a third examination fused chromic acid was applied to the vascular area; when the slough separated a firm cicatrix formed, and hæmoptysis did not again occur up to the time of the patient's death in 1888, from secondary septic renal disease. Post mortem, old pleuritic addences of old or recent tuberculous disease, or other lesions in the lungs.

Tumours composed of blood vessels are seldom met with in the nasal mucous membrane, and very rarely give rise to hæmorrhage of the kind that we are now considering. It might be expected that vascular tumours, such as the angiomata, would readily develop in erectile tissues such as the corpus cavernosum or clitoris, or the spongy turbinated bodies, but as a clinical fact these tissues are markedly exempt from nævous growths, and the most frequent seats of the capillary vascular tumours are in the subcutaneous tissues of the scalp, face, or trunk.

In the case about to be described the tumour was not found on the highly vascular part of the turbinated body, but was attached to the posterior aspect, where the blood supply is comparatively small. It is of interest, not only as a cause of severe hæmorrhage, but also on account of the almost unique character of the growth from which the blood escaped.

CAsE vi. Angioma of the Posterior Part of the Left Turbinated Body, causing Repeated Hamoptyses during Eighteen Months, Phthisis strongly suspected : Emaciation and Ancmia of Mucous Membrane of Larynx, Pharynx, etc.; Bleeding stopped by Removal of Tumour.-C. R., aged 27, was sent to me at the had been suffering from hæmoptysis for eighteen months previous to
November, 1890. Sometimes the patient coughed up a considerable quantity of pare blood (the exact amount unknown), at other times the blood was small in quantity and intimately mixed with very tough mucus. Generally the hæmoptysis occurred on awaking in the morning, but once or twice the bleeding happened during the day, when the patient had been over-exerting himself. At these times he had cough, pain in the throat, and difficulty in swallowing. Emaciation and anæmia were well marked. The sputa contained no tuberculous bacilli, but the existence of phthisis was strongly suspected. On examination of the throat the mucous membranes of the pharynx, palate, and larynx were seen to be very anæmic, while the margins of the pillars were of a bright red colour, but there was no tuberculous swelling at any part. The marked anæmia was, however, very suggestive of tuberculous disease. There was extensive granular pharyngitis. Examination of the posterior nares showed enlargement of the inferior turbinated body, and at its posterior limit there was a growth of the size and shape of a haricot very much the appearance of a ripe bramble, and on being touched very much the appearance of a ripe bramble, and on being touched considerably obstructed in front by the enlargement of the inferior turbinated body. Examination of the lungs revealed a small area of diminished resonance at the right apex in front, with no rales, but a slight proongation of expiration only ; otherwise no objective or subjective evidences of tuberculous disease. The granular pharyngitis and the hypertrophy of the turbinated body were treated by the local application of fused chromic acid. Afterwards the growth was removed with an electric snare, and subsequently the base was cauterised several times, until no remnant of the vascular tissue remained. The patient reported himself well in September, 1893 , having had no hæmoptysis since a week after the had gained 9 lbs. in weight.

In all cases of hæmoptysis the important point to determine is the source of the bleeding. In the cases just described not infrequently the blood escaped in such a way as, had the cause been suspected, at once to suggest the nature of the hæmoptysis, but sometimes in the same case the blood trickled down into the larynx or trachea, and was expectorated as if from the lungs. Hence the mode in which the blood escapes, or even the impressions of the patient, cannot be taken as a guide in determining the source of the bleeding ; it therefore becomes all the more important to carefully employ the laryngoscope or the rhinoscope to establish the precise lesion from which the blood flows. It is believed by many that if blood is seen in the trachea we may conclude that the hæmoptysis is from the lungs. This is not altogether correct. The blood, as I have shown in some of the foregoing cases, may flow into and even collect in the trachea from the higher air passages, but it may be asserted as a general rule that during pulmonary hæmoptysis the trachea is blnod-stained, and the blood is intimately mixed with the mucus. Whereas in hæmorrhage from the larynx or the parts above it, the trachea is seldom stained, the blood expectorated is pure, only on the surface of a mass of mucus, inspissated, or in dry clots. In all cases if the source of the bleeding is in the larynx or upper parts of the air passages, the laryngoscope should reveal its source, but perhaps not with one examination only, many careful observations may be required.

In the great majority of cases it is easy to distinguish a pulmonary hæmorrhage from other hæmoptysis, but in a few nstances the distinction between the two forms of bleeding is a matter of considerable difficulty. In the absence of any lesion in the upper air passages to account for it, the bleeding may be safely attributed to a pulmonary lesion, even although there may be no appreciable evidence of disease in the lungs, and on this assumption treatment should be adopted until unmistakable symptoms or physical signs render the diagnosis certain.

REFERENCES.

THE annual general meeting of the St. George's Hospital Graphic Society will be held at the hospital on Tuesday, June ist, at 2.30 P.M. By permission of the Board of Governors the annual exhibition, which is strictly limited to the work of members, will be held in the Board Room of the hospital. The exhibition will be opened immediately after the meeting, and will remain open until the end of the week.

THe Sociedad Cientifica Argentina is organising a LatinAmerican Scientific Congress, to be held in Buenos Ayres in April, 1898, under the patronage of the President of the Republic, and the honorary presidency of the Minister of Justice, Worship, and Public Instruction. One section will be allotted to medicine and surgery, and another to anthropology. 